\title{
Glutamate Sensing Electrode with an Electroconductive Membrane Containing Glutamate Dehydrogenase, NADP and Phenazine Methosulfate
}

\author{
Soichi YABUKI, Fumio MIZUTANI and Michihiko ASAI
}

Received June 28, 1990 ; Accepted August 20, 1990

\section{INTRODUCTION}

Recently, much effort has been directed to the construction of amperometric biosensors with the use of electron mediator that mediate electron between the cofactor of enzyme and electrode. An amperometric biosensor, including $\mathrm{NAD}(\mathrm{P}) \mathrm{H}$ regeneration system, is of interest in utilizing $\mathrm{NAD}(\mathrm{P})$ type enzyme: over 250 dehydrogenases should be able to be applied to biosensors. It is effective to use some mediators ${ }^{1}$ ) such as phenazine methosulfate ${ }^{2)}$, Meldola's blue ${ }^{3)}$ methylene blue ${ }^{4}$ for the electrochemical oxidation of $\mathrm{NAD}(\mathrm{P}) \mathrm{H}$. An amperometric biosensor requires a membrane system containing enzyme, coenzyme, and mediator. We have reported a preparation method of polypyrrole membrane containing enzyme, $\mathrm{NAD}$, and mediator ${ }^{5}$, in which electrons transfer between enzyme and polypyrrole via NAD, and mediator. In this paper, we report the construction of a glutamate sensing electrode with an electroconductive membrane containing glutamate dehydrogenase, NADP, and mediator.

\section{EXPERIMENTAL}

A polypyrrole membrane containing glutamate dehydrogenase (G1DH), NADP and phenazine methosulfate (PMS) was prepared as follows. GlDH $(60 \mathrm{U} / \mathrm{ml}$, TOYOBO Co., Type II, EC 1.4.1.4) was dissolved in a deoxygenated $0.1 \mathrm{M}$ potassium chloride solution containing $0.1 \mathrm{M}$ pyrrole, $10 \mathrm{mM}$ PMS, and $3 \mathrm{mM}$ NADP ( $\mathrm{U}$ corresponds to the loss of $1 \mu \mathrm{mol}$ of glutamate $/ \mathrm{min} . M=$

Research Institute for Polymers and Textiles, Higashi 1-1-4, Tsukuba, Ibaraki 305, Japan

Key Words : Electroconductive membrane, Glutamate sensor, Glutamate dehydrogenase, Phenazine methosulfate $\mathrm{mol} / \mathrm{dm}^{3}$ ). A platinum disk (diameter was $1.7 \mathrm{~mm}$ ) was used as a working electrode. An Ag/AgCl electrode was used as a reference. For the electrochemical polymerization of pyrrole, the potential of $+0.8 \mathrm{~V} \mathrm{vs}$. $\mathrm{Ag} / \mathrm{AgCl}$ was set on the platinum electrode. The charge passed was $20 \mathrm{mC}$ for the preparation. The platinum electrode coated with a polypyrrole layer, in which GIDH, NADP, and PMS were immobilized (PPy-GlDH), was rinsed with a $0.1 \mathrm{M}$ borate buffer $(\mathrm{pH}=$ 8.0).

The enzyme activity of the PPy-GlDH membrane was measured in a buffer solution containing $1 \mathrm{mM} \mathrm{NADP}$, and $20 \mathrm{mM}$ glutamate.

The current response to glutamate with PPy-GIDH membrane was examined in a deoxygenated $0.1 \mathrm{M}$ glycine- $\mathrm{NaOH}$ buffer $(\mathrm{pH}$ $=9.5$ ), which was stirred gently at $40^{\circ} \mathrm{C}$. A potential of $+0.3 \mathrm{~V}$ vs. $\mathrm{Ag} / \mathrm{AgCl}$ was set on the PPy-GlDH membrane. After 10 minutes, glutamate was added in the solution.

\section{RESULTS AND DISCUSSION}

Mediators such as dichlorophenolindophenol or Meldola blue, except for PMS, were inactive in a $0.1 \mathrm{M}$ glycine- $\mathrm{NaOH}$ buffer $(\mathrm{pH}$ =9.5) solution, so that PMS was co-immobilized in a polypyrrole membrane.

The GlDH activity in the polypyrole membrane was measured. At $\mathrm{pH} 9.5$ (the optimum $\mathrm{pH}$ of PPy-GlDH membrane as well as of free GlDH), the PPy-GlDH membrane exhibited the activity of $35 \mathrm{mU} \cdot \mathrm{cm}^{-2}$.

Current response to glutamate with the PPy-GIDH membrane was then measured. After 5 minutes of glutamate addition, oxidative current reached a maximum value, and then gradually decreased. The reason for the gradual decrease in current response has not yet been known. The oxidation current increase was specific to glutamate addition: glutamine or norvaline did not 


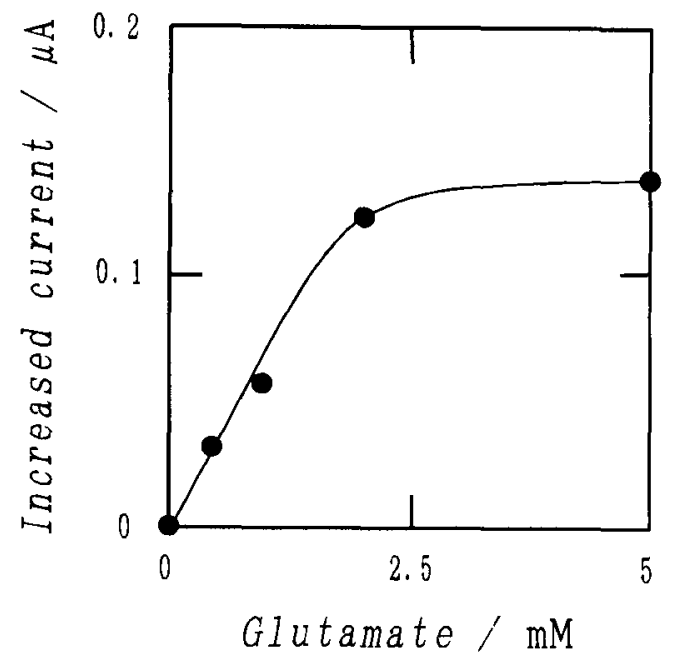

Fig. 1 Oxidative current increase caused by the addition of glutamate to the polypyrrole membrane containing glutamate dehydrogenase, NADP and PMS.

induce any current increase. Furthermore, in the absence of NADP or PMS, the current did not increase whenever glutamate was added. It is clear that electrons was transferred from enzyme to mediator via coenzyme after the glutamate addition. Fig. 1 shows the oxidation current dependency of the PPy-GlDH membrane on the glutamate at the potential of $+0.3 \mathrm{~V}$ vs. $\mathrm{Ag} / \mathrm{AgCl}$. The detection range of glutamate by this system was from 0.5 to $2 \mathrm{mM}$. Below $0.5 \mathrm{mM}$ glutamate, the response was too small compared with noise to measure the current increase accurately. Thus, it may be advantageous to apply the present glutamate sensor system with the PPy-GIDH membrane.

The effect of electrode potential on the current response was examined. Fig. 2 shows the current increase upon addition of $2 \mathrm{mM}$ glutamate at various potentials. Redox potential of PMS in glycine- $\mathrm{NaOH}$ buffer $(\mathrm{pH}$ $=9.5$ ) was $-0.15 \mathrm{~V}$ vs. $\mathrm{Ag} / \mathrm{AgCl}$. In the potential range more positive than $-0.15 \mathrm{~V}$ vs. $\mathrm{Ag} / \mathrm{AgCl}$, a response to glutamate was detected. These results indicate the oxidative current increase was due to the oxidation of PMS in the membrane. The detection with the PPy-GIDH membrane in the low potential region (around $\mathrm{O} \mathrm{V}$ vs. $\mathrm{Ag} / \mathrm{AgCl}$ ) would be effective for reducing the effect from the interferences such as ascorbate.

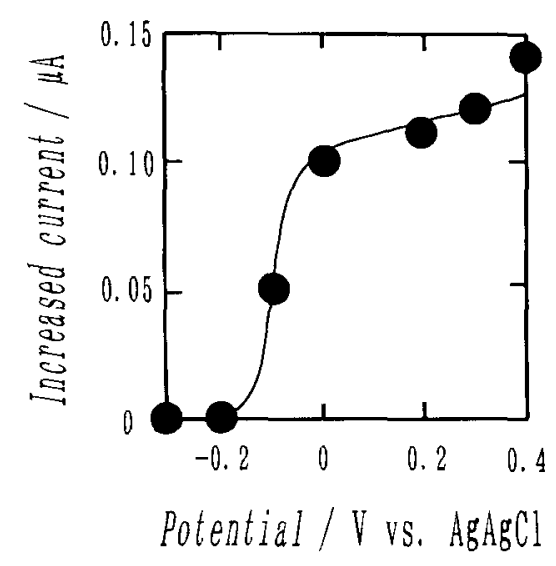

Fig. 2 Current response to glutamate with the polypyrrole membrane containing glutamate dehydrogenase, NADP and PMS at various potentials. 5 minutes after the addition of $2 \mathrm{mM}$ glutamate (final concentration), the current increase was measured.

Enzyme activity of PP-GlDH membrane was decreased by $10 \%$ per 2 hours when the membrane was immersed in a buffer solution; accordingly, the current reduced by 5 $\%$ Although it is considered to leak of GlDH, NADP, and PMS from the membrane, this method is effective and easy to entrap enzymes in an electoconductive membrane. It would be required to get leakage-less membrane by developing preparation method.

From these results, it is concluded that the electron from glutamate was transferred to polypyrrole via GlDH, NADP and PMS in the polypyrrole membrane. The polypyrrole membrane containing glutamate dehydrogenase, NADP, and PMS could be applied to an amperometric glutamate sensor.

\section{REFERENCES}

1) M. Aizawa and Y. Ikariyama, Coenzymes Cofactors, 2, 203 (1987).

2) H. Huck, A. Schelte-Graf, D. Danzer, P. Krich and H. L. Schmidt, Analyst, 109, 149 (1984).

3) L. Gorton, A. Torstensson, H. Jaegfeldt and G. Johansson, J. Electroanal. Chem., 161, 103 (1984).

4) L. G. Lee and G. M. Whitesides, J. Am. Chem. Soc., 107, 6999 (1985).

5) S. Yabuki, H. Shinohara, Y. Ikariyama and M. Aizawa, J. Electroanal. Chem., 277, 179 (1990). 